\title{
Evaluation of Fetal Transcerebellar Diameter as a Sonological Parameter for the Estimation of Fetal Gestational Age in Comparison to Fetal Biometry
}

\author{
Rajendra T.M ${ }^{1}$ \\ ${ }^{1}$ Post Graduate, Department of Radiodiagnsis, Pesimsr - Kuppam, Andhra Pradesh, India \\ Corresponding author: Dr Mallikarjunappa, Professor, Radio-Daignosis, Pesimsr - Kuppam, Andhra Pradesh, India
}

DOI: http://dx.doi.org/10.21276/ijcmsr.2019.4.4.16

How to cite this article: Rajendra T.M. Evaluation of fetal transcerebellar diameter as a sonological parameter for the estimation of fetal gestational age in comparison to fetal biometry. International Journal of Contemporary Medicine Surgery and Radiology. 2019;4(4):D66-D70.

\section{A B S T R A C T}

Introduction: The most important parameter needed for appropriate management of pregnant women is accurate Gestational Age and its significance in accurately determining gestational age and its contribution to the detection of the small-for-gestational age.The aim of our study is Evaluation of Fetal Transcerebellar Diameter as a Sonological Parameter for the Estimation of Fetal Gestational Age in Comparison to fetal biometry

Material and Methods: A prospective study was carried out in 798 pregnant women between 15 to 40 weeks of gestation, who came for routine antenatal sonography during six months of july 2018 to31dec 2018 . Transcerebellar diameter was measured along with routine parameters as laid down in standard textbooks. Subjects were divided into five groups based on GA. 16-20 weeks, 21 - 25 weeks, 25 - 30 weeks, 31 - 35 weeks and >36 Weeks. Gestational age using TCD and other parameters was calculated and compared with gestational age based on Last Menstrual Period (LMP). Correlation between the GA by LMP with GA by other ultrasound parameters was done by using Karl Pearson's Correlation( $r$ ). nomograms were also done. Results: Statistically significant relationships between transverse cerebellar diameter and gestational age, abdominal circumference and head circumference were found. . No statistically significant difference in perinatal mortality or birth weight was found between the subsets of growth-restricted fetuses with reduced or normal TCD Conclusion.

Conclusion: TCD is an accurate parameter in estimation of gestational age in second and third trimesters as its values are in close relation with that of GA by LMP. It is also better predictor of the gestational age when compared to other parameters especially in third trimester.

Keywords: Fetal Transcerebellar Diameter, Sonological Parameter, Fetal Gestational Age, Fetal Biometry

\section{INTRODUCTION}

GA is an important parameter in obstetrics for management of pregnancy and evaluating foetal development . High incidence of perinatal mortality has been noted in patients whose accurate gestational age is not known. Uncertain gestational age is associated with preterm delivery, low birth weight and post maturity. ${ }^{1-4}$

Sonographic estimation of GA by using foetal biometric parameters such as $\mathrm{BPD}, \mathrm{FL}, \mathrm{AC}$ and $\mathrm{HC}$ assumed important role in management of pregnancy. There are some limitations with these parameters as BPD after 26 weeks becomes unreliable in conditions altering the shape of skull, young age and breech presentation. Femur length is shortened in cases of achondroplasia making it unreliable parameter in estimating GA. The accurate measurement of these parameters depends a lot on fetal lie, shape of skull, location of placents, flexion of fetal head and engagement, maternal obesity and multiplicity of gestation. More recently another fetal patameter, trans cerebellar diameter (TCD) has evolved as a promising indicator for assessing fetal growth and gestational age..$^{5-9}$

TCD can be used as an independent parameter against which other established parameters can be compared when gestational age cannot be calculated by LMP. $^{10-12}$

TCD is least affected by IUGR, so the POG calculated from TCD can act an internal check for other fetal parameters in establishing IUGR. ${ }^{12}$

The aim and objective of the present study were to evaluate the usefulness of transcerebellar diameter as against the conventional parameters of biparietal diameter, abdominal circumference and femur length in normal pregnant mothers between 15 to 40 weeks, to evaluate the usefulness of transcerebellar diameter in antenatal diagnosis of intrauterine growth retardation, to derive normograms for estimating the gestational age of the fetus from the measured transcerebellar diameter.

\section{MATERIAL AND METHODS}

The study was conducted in our teaching hospital from Jul 2018 to Dec 2018. Pregnant women of gestational age 15 to 
$>36$ weeks of pregnancy referred from Dept of Obstetrics and Gynae for antenatal scan comprised present study sample. The sampling frame was bound by the following inclusion and exclusion criteria.

\section{Inclusion criteria}

Normal singleton pregnancies of 15- and 40-weeks' gestation with known last menstrual period. Clinically suspected intrauterine growth retardation.

\section{Exclusion criteria}

Congenital malformations, Multiple pregnancies.

The study was conducted on 798 pregnant women normal and 48 IUGR pregnancies.

Ultrasound examinations were carried out using a with a 3.5 or 5.0 MHz transducer. Fetal biometry included measurement of the BPD (mm), HC (cm), TCD (mm), AC (mm) and FL $(\mathrm{mm})$. The BPD and HC were measured from a transverse cross-section of the fetal head at the level of the thalamus and cavum septi pellucidi. By slightly rotating the transducer from the thalamic plane, the posterior fossa became visible, enabling the characteristic shape of the cerebellum to be imaged. The TCD was measured in an 'outer-to-outer' fashion. The abdominal circumference was obtained from a transverse section at the level of the junction of the umbilical vein and left portal vein. Ultrasound examinations were carried out using a voluson $730 \mathrm{PRO}$.

The analysis of data were done as follows, TCD in mm was correlated with expected gestational age and fetal biometry. The subjects were divided into five groups based on gestational age at the time of ultrasound scan into 15-20weeks,2125weeks, 25-30 weeks,31-35 weeks and >36 weeks.

\section{STATISTICAL ANALYSIS}

Statistical analysis was performed using SPSS software version 17.0 Statistical analysis was done by using Karl Pearson's coefficient of correlation ( $r$ ) and regression analysis. Significance level was considered at $\mathrm{p}$ value $<0.05$.

\section{RESULTS}

Age group distribution and their percentage during different weeks of gestation shows that our study included cases of all weeks in reasonable number, which gave strength to the authenticity of result [Table 1]. Table 1 shows the age wise distribution of women enrolled in the study. Age of women ranged from 18 to 42 years with maximum number of patients were aged $15-20$ weeks years $(n=154 ;---\%)$ followed by those aged $16-20$ years $(n=173 ; 22 \%), 26$ to $30(n 147$; $18 \%), 31-35$ weeks $(n=134.17 \%)$ and $>36$ years $(n=112 ; 14 \%)$ (Table 2). Similarly parity wise distrution shows highest reported cases are of gravid 2. Table 3.

Gestational age of cases ranged from 15 weeks 6 days to 40 weeks 2 days. Maximum number of cases were in gestational age 21-25 weeks (29\%) followed by those in 16-20 weeks $(n=47 ; 23.5 \%),>20-25$ weeks $(n=34 ; 17 \%)$ and $>28-32$ weeks ( $\mathrm{n}=25 ; 12.5 \%)$ respectively.

Mean and Standard Deviation for each group week of gestation shows that TCD in $\mathrm{mm}$ is equal to Gestational Age in weeks during 14-24 weeks [Table 2].

The Karl Pearson Correlation coefficient between TCD and
GA was 0.9388. 4. Pair wise comparison between TCD and Gestational Age shows probable value of 'p' (unpaired) as 0.0000 and $p$ value being 0.98 (<.0001 i.e. highly significant). Regression analysis was done for Trans-Cerebellar Diameter and Gestation Age. Formula obtained was $\mathrm{X}=$ 0.7118Y + 6.8091 $(\mathrm{X}=$ Gestation Age $; \mathrm{Y}=$ Trans Cerebellar Diameter).

Graphical representation of collected data between Gestation Age and Transverse Cerebellar Diameter shows linear relationship. In IUGR cases: Mean and Standard Deviation of TCD in mm were $28 \pm 1.87$ for $25-28$ weeks, $34.47 \pm 1.68$ for 29-32 weeks, $40.54 \pm 3.01$ for $33-36$ weeks and $45 \pm 0.82$ for 37-40 weeks (graph-1).

\begin{tabular}{|l|c|}
\hline Age of pregnant patients & No of patients $\mathbf{n = 7 9 8}$ \\
\hline$<20$ yrs & $154(20 \%)$ \\
\hline $21-25$ years & $334(42 \%)$ \\
\hline $26-30$ years & $250(31 \%)$ \\
\hline 31 to35 years & $50(6 \%)$ \\
\hline 36 years & $10(0.7 \%)$ \\
\hline \multicolumn{2}{|c|}{ Table-1. Showing age-wise details } \\
\hline
\end{tabular}

\begin{tabular}{|l|c|}
\hline Group & No of patients n=798 \\
\hline 16 Weeks to 20 weeks & $173(22 \%)$ \\
\hline 21 weeks to 25 weeks & $232(29 \%)$ \\
\hline 26 weeks to 30 weeks & $147(18 \%)$ \\
\hline 31 weeks to 35 weeks & $134(17 \%)$ \\
\hline Above 36 weeks & $112(14 \%)$ \\
\hline Total & 798 \\
\hline \multicolumn{2}{|c|}{ Table-2: Study of population group } \\
\hline
\end{tabular}

\begin{tabular}{|l|c|c|}
\hline Parity & Normal pregnancies & IUGR patientsn=48 \\
\hline Gravida 1 & $349(43 \%)$ & 24 \\
\hline Gravida 2 & $345(43 \%)$ & 18 \\
\hline Gravid 3 & $69(8 \%)$ & 4 \\
\hline Gravida 4 & $35(4 \%)$ & 2 \\
\hline Total & 798 & \\
\hline \multicolumn{2}{|c|}{ Table-3: Parity distribution of normal and IUGR pregnant } \\
patients \\
\hline
\end{tabular}

\begin{tabular}{|l|c|c|}
\hline Parameters & R value & p value \\
\hline TCD vs BPD & 0.9051 & $<0.001$ \\
\hline TCD vs HC & 0.8927 & $<0.001$ \\
\hline TCD vs AC & 0.9142 & $<0.001$ \\
\hline TCD vs FL & 0.8940 & $<0.001$ \\
\hline \multicolumn{2}{|c|}{ Table-4: Correlation coefficient between TCD and various } \\
biometric parameters \\
\hline
\end{tabular}

\begin{tabular}{|l|c|c|}
\hline Parameters & P value & R value \\
\hline GA VERSUS BPD & $<0.001$ & 0.9785 \\
\hline GA VERSUS HC & $<0.001$ & 0.9630 \\
\hline GA VERSUS AC & $<0.001$ & 0.9830 \\
\hline GA VERSUS FL & $<0.001$ & 9694 \\
\hline $\begin{array}{l}\text { Table-5: Correlation of gestational age (by LMP) by estimated } \\
\text { gesational age based on different fetal biometric parameters } \\
\text { (all pregnancies): composite gestational age (biometry). }\end{array}$ \\
\hline
\end{tabular}




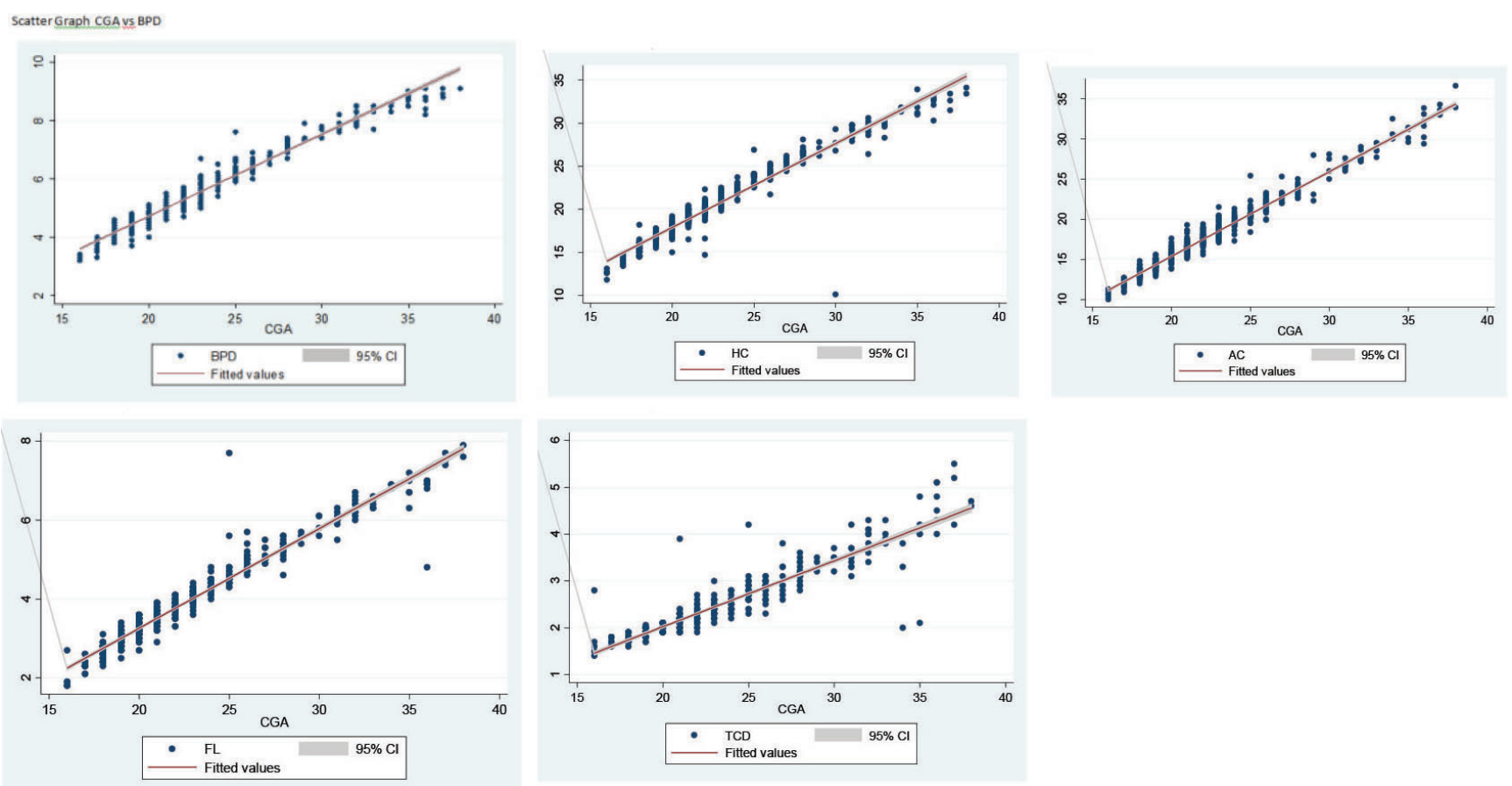

Graph-1: Scatter graph CGA vs BPD,HC,AC,FL and TCD showing curvilinear relationship. Nomogram showing TCD measurements at 5 th, 50 th, 95 th percentile for corresponding gestational age.

\begin{tabular}{|l|c|c|c|c|c|}
\hline CGA (CGA) & Mean & Std Dev & Frequency.n=798 & p & r \\
\hline 16-20 Weeks & 4.3260116 & 0.40815059 & 173 & $<0.001$ & 0.9785 \\
\hline 21-25 Weeks & 5.4755365 & 0.49944175 & 285 & $<0.001$ & 0.9810 \\
\hline 26-30 Weeks & 6.854902 & 0.44195643 & 151 & $<0.001$ & 0.9965 \\
\hline 31-35 Weeks & 8.2 & 0.39304295 & 80 & $<0.001$ & 0.9710 \\
\hline 36+Weeks . & 8.8454545 & .31101008 & 109 & $<0.001$ & 0.9700 \\
\hline \multicolumn{7}{|l}{} \\
\hline
\end{tabular}

\begin{tabular}{|l|c|c|c|}
\hline CGA & Mean & Std Deviation & $\begin{array}{c}\text { Frequency } \\
\mathbf{n = 7 9 8}\end{array}$ \\
\hline $16-20$ Weeks & 14.141618 & 1.3994607 & 173 \\
\hline $21-25$ Weeks & 17.994893 & 1.6551331 & 285 \\
\hline 26-30 Weeks & 23.072549 & 1.7277822 & 151 \\
\hline 31-35 Weeks & 8.42 & 1.773055 & 80 \\
\hline 36+Weeks & 32.884545 & 1.9942987 & 109 \\
\hline Table-7: Distribution of study population according to gesta- \\
tional age by LMP with AC. \\
\hline
\end{tabular}

\section{DISCUSSION}

Professor Ian Donald of Glassgow was the first to use diagnostic ultrasonography to investigate gravid uterus and is considered as father of modern ultrasound. Along with Mac Vicar and Brown, he developed first 2D contact scanner in 1958. Foetal cerebellum is sonographically visualized as early as $10-11$ weeks. $^{7}$ TCD is least affected by factors affecting foetal growth allowing it to determine accurate gestational age even in third trimester and cases of intrauterine growth restriction. $^{7}$

Accurate determination of gestational age is essential in the care and management of the pregnant patient. Information on gestational age allows the clinician, to both date the pregnancy and distinguish normal from abnormal growth

\begin{tabular}{|l|c|c|c|}
\hline CGA & Mean & Std Deviation & $\begin{array}{c}\text { Frequency } \\
\mathbf{n = 7 9 8}\end{array}$ \\
\hline 16-20 Weeks & 2.9179191 & 0.38800661 & 173 \\
\hline 21-25 Weeks & 3.9128755233 & 0.46886406 & 285 \\
\hline 26-30 Weeks & 5.1901961 & 0.36069649 & 151 \\
\hline 31-35 Weeks & 6.39 & 0.37448816 & 80 \\
\hline 36+Weeks & 7.0472727 & 0.83317574 & 109 \\
\hline Table-8: Distribution of study population according to gesta- \\
tional age by LMP with FL. \\
\hline
\end{tabular}

\section{patterns.}

Our study spanned over six months and included fetuses with gestational age between $15->36$ weeks is a prospective longitudinal study where TCD in fetal dating.

The biometric parameters used for gestational age assessment are BPD, HC, AC and FL. However each of these parameters have their own limitation. The variability in predicting gestational age with these parameters goes on increasing as the pregnancy advances.

In our study there was significant correlation between $\mathrm{GA}$ vs BPD $p=0.001$. $r=0.9785$. GA versus HC $p=0.001 r=0.9785$. GA versus $A C p=0.001 r=0.9830$ and $G A$ versus FL $p=0.001$ $r=9694$.

Our study showed good Correlation co-efficiency between TCD and various biometric parameters i.e. TCD vs BPD 


\begin{tabular}{|l|c|c|c|}
\hline CGA & Mean & Std Deviation & $\begin{array}{c}\text { Frequency } \\
\mathbf{n = 7 9 8}\end{array}$ \\
\hline 16-20 Weeks & 1.8968786 & 0.15540484 & 173 \\
\hline 21-25 Weeks & 2.3300429 & 0.28534386 & 285 \\
\hline 26-30 Weeks & 3.0470588 & 0.32701862 & 151 \\
\hline $31-35$ Weeks & 3.7166667 & 0.58373549 & 80 \\
\hline $36+$ Weeks & 4.7272727 & 0.46495357 & 109 \\
\hline GA & $5^{\text {th }}$ & $50^{\text {th }}$ & $95^{\text {th }}$ \\
percentile & percentile & percentile \\
\hline Group 1 & 18.4 & 20.4 & 23.8 \\
\hline Group 2 & 21 & 22 & 25 \\
\hline Group 3 & 25 & 27 & 30 \\
\hline Group 4 & 31 & 32 & 35 \\
\hline Group 5 & 36 & 36 & 38 \\
\hline \multicolumn{4}{|c|}{ Table-9: Distribution of study population according to gesta- } \\
tional age by LMP with TCD. \\
\hline \multicolumn{4}{|c|}{} \\
\hline
\end{tabular}

$\mathrm{r}=0.9051, \mathrm{p}=<0.001, \mathrm{TCD}$ vs HC r=0.8927 $\mathrm{r}=<0.001$, TCD vs $\mathrm{AC} \mathrm{r}=0.9142 \mathrm{p}=0.001$, TCD vs FL $\mathrm{r}=0.8940 \mathrm{p}=0.001$.

Mcleary et $\mathrm{al}^{1}$ study showed Transcerebellar diameter may be useful in estimating fetal gestational age particularly in breech presentation where extrinsic pressure may deform the skull and decrease the biparietal diameter.

Reece et $\mathrm{al}^{3}$ study of TCD in normal pregnant women showed curvilinear relationships between the transverse diameter of the cerebellum and the gestational age $(\mathrm{R} 2=0.948, \mathrm{P}=0.001)$, biparietal diameter $(\mathrm{R} 2=0.956, \mathrm{P}=0.0001)$, and the head circumference $(\mathrm{R} 2=0.969, \mathrm{P}=0.0001)$.

Nomogram was established which shows mean TCD values at $5^{\text {th }}, 50^{\text {th }}$ and $95^{\text {th }}$ percentile for the corresponding gestational age. The nomogram can be used for assessing the fetal gestational age when LMP is not known and to assess any deviation from normal growth. Smith ${ }^{2}$ study of and Reece $^{3}$, et al. study Nomogram of Transcerebellar diameter measurement against the gestational age showed good correlation and narrow confidence limits.

Gupta AD et al. ${ }^{10}$ Naseem F et al ${ }^{11}$, compared GA by TCD and BPD with LMP. In this study, they observed that in 228 patients, when compared with GA by LMP, TCD had given accurate gestational age in 209 patients and BPD had given accurate gestational age in 176 patients similar to our study.

Bansal A, et $\mathrm{al}^{12}$, R Nagesh ${ }^{13}$, Rami reddy ${ }^{14}$ et al Sunita Dashottar, Prasad, Vijay Kothan et al Sumanta Kumar Manda ${ }^{15}$ et al and .Vijay Kothanet $\mathrm{al}^{16}$ demonstrated that a linear relationship was found between TCD and fetal gestational age between 15 to 40 weeks of normal gestation $(\mathrm{r}=0.992, \mathrm{p}<0.001)$.

\section{CONCLUSION}

Our study showed that TCD is an accurate predictor of gestational age in the second and third trimester. The correlation between the LMP derived gestational age and the gestational age by TCD seems to decrease from second to third trimester. Even in the third trimester TCD is fairly accurate and better predictor of gestational age in comparison to the other ultrasound parameters such as BPD, HC, AC, FL.FL, though accurate, cannot be used as a single parameter for estimation of gestational age as it is the parameter that is most affected by IUGR. TCD is the parameter that is least affected by IUGR, therefore can be used as a single parameter for the estimation of gestational age. Our results also showed that TCD is not affected by age of the mother and parity also does not seem to have an effect on TCD.

\section{REFERENCES}

1. Mcleary RD, Kuhns LR, Barr M. Ultrasonography of the fetal cerebellum. Radiology, 1984; 151(1): 439-442

2. Smith PA, Johansson D, Tzannatos C, Campbell S. Prenatal measurement of the fetal cerebellum and cisterna cerebellomedullaris by ultrasound. Prenat Diagn., 1986; 6(2): 133- 141.

3. Reece EA, Goldstein I, Pilu G, Hobbins JC. Cerebellar measurements with ultrasonography in the evaluation of fetal growth and development.AM.J. Obstet. Gynaecol., 1987; 156(6): 1065-1069

4. Hashimoto K, Shimizu T, Shimoya K, Kanzaki T, Clapp JF, Murata Y. Foetal cerebellum:us appearance with advancing gestational age 1. Radiology. 2001;221(1):7074 K, Shimizu T, Shimoya K, Kanzaki T, Clapp JF, Murata Y. Foetal cerebellum:us appearance with advancing gestational age 1. Radiology. 2001;221(1):7074.

5. Davies MW, Swaminathan M, Betheras FR. Measurement of transverse cerebellar diameter in preterm Neonates and it's use in assessment of gestational age. Australian Radiology. 2001;45(3):30912.

6. Hashimoto K, Shimizu T, Shimoya K, Kanzaki T, Clapp JF, Murata Y. Foetal cerebellum:us appearance with advancing gestational age 1. Radiology. 2001;221(1):7074.

7. Davies MW, Swaminathan M, Betheras FR. Measurement of transverse cerebellar diameter in preterm Neonates and it's use in assessment of gestational age. Australian Radiology. 2001;45(6):309_ 12.

8. Kalish RB, Chervenak FA. Sonographic determination of gestational age. The Ultrasound Review of Obstetrics \& Gynecology. 2005;5(4):254-58

9. Chavez MR, Ananth CV, Smulian JC, Vintzileos AM. Fetal transcrebellar diameter measurement for prediction of gestational age at the extremes of fetal growth. J ultrasound Med., 2007; 26(9): 1167-71.

10. Gupta AD, Banerjee A, Rammurthy N, Revati P, Jose J. Gestational age estimation using transcerebellar diameter with grading of foetal cerebellar growth. National Journal of Clinical Anatomy. 2012;1(3):11520.

11. Naseem F, Ali S, Basit U, Fatima N. Assessment of gestational age;comparison between transcerebellar diameter versus femur length on ultrasound in third trimester of pregnancy. Professional Med J. 2014;21(2):412-17.

12. Bansal M, Bansal A, Jain S, Khare S, Ghai R. A study of correlation of transversecerebellar diameter with gestational age in the normal and the growth restricted fetuses in western Uttar Pradesh. PJSR, 2014; 7(2): 16-1

13. R Nagesh, S Pramila VV, Anil Kumar Shukla.Transverse 
cerebellar diameter - As an ultrasonographic parameter for estimation of fetal gestational age. International journal of contemporary medical research, 2016; 3.

14. Reddy RH, Significance of Foetal Transcerebellar Diameter in Foetal Biometry: A Pilot Study. J Clin Diagn Res. 2017;11(6):TC01-TC04.

15. Sunita Dashottar, Transcerebellar diameter: an effective tool in predicting gestational age in normal and IUGR pregnancy, Int J Reprod Contracept Obstet Gynecol. 2018 Oct;7(10):4190-4196.

16. Sumanta Kumar Mandal, Evaluation of Fetal Transcerebellar Diameter as a Sonological Parameter for the Estimation of Fetal Gestational Age in Comparison to Biparietal Diameter and Femur Length, IAIM, 2019; 6(6): 41-50.

17. Vijay Kothan. Comparison of sonographic measurement of TCD and FL with biometric parameters for the estimation of gestational age in pregnant women. EJOG 2019;234(1):136-9.

Source of Support: Nil; Conflict of Interest: None

Submitted: 26-09-2019; Accepted: 15-10-2019; Published online: 13-11-2019 